\title{
An 8-Year-Old Girl with Autoimmune Hepatitis Following Aplastic Anemia
}

\author{
Ayako Nishigori ${ }^{1}$, Tsutomu Hatori ${ }^{2}$ and Takeshi Asano ${ }^{1}$ \\ ${ }^{1}$ Department of Pediatrics, Nippon Medical School Chiba Hokusoh Hospital, Chiba, Japan \\ ${ }^{2}$ Department of Pathology, Nippon Medical School Chiba Hokusoh Hospital, Chiba, Japan
}

We herein report a case of severe aplastic anemia diagnosed in an 8-year-old girl with a previous diagnosis of autoimmune hepatitis. We found significantly increased CD8+ and CD68+ cell numbers in her bone marrow, which can induce severe organ damage, refractory to immunosuppressive therapy.

(J Nippon Med Sch 2018; 85: 241-244)

Key words: autoimmune hepatitis, aplastic anemia, macrophage, child

\section{Introduction}

Autoimmune hepatitis is active hepatitis characterized serologically by the presence of circulating autoantibodies. Histologically, this disorder exhibits dense mononuclear cell infiltrates in the portal tracts and progressive destruction of the hepatic parenchyma. Without treatment, autoimmune hepatitis often progresses to cirrhosis. Reported cases of autoimmune hepatitis in children are extremely rare ${ }^{1}$.

Hepatitis-associated aplastic anemia is also rare, accounting for $3-5 \%$ of all aplastic anemia cases ${ }^{2}$. Patients typically develop severe aplastic anemia 2 to 3 months after an episode of acute hepatitis. If untreated, hepatitisassociated aplastic anemia is often fatal and presents within a few months after the onset of hepatitis.

Here, we report a case of aplastic anemia diagnosed in an 8-year-old girl with a previous diagnosis of autoimmune hepatitis. Although she was treated with antithymoglobulin with cyclosporine, no hematological improvement was observed. She was then treated with hematological stem cell transplantation from a human leukocyte antigen (HLA) identical sibling, and subsequently exhibited a normal hematopoiesis condition as well as improvement of her hepatitis. We found an increased ratio of CD68-positive cells in initial bone marrow specimens when compared to another patient with aplastic anemia who showed an improved hematological condition after treatment with anti-thymoglobulin and cyclosporine.

\section{Case}

An 8-year-old girl was admitted to our hospital because of jaundice and general fatigue. There was no family history of hepatitis, autoimmune disease, or hematological disorders. She had not received any blood transfusions. On admission, her skin and ocular bulbs were icteric, and there was no hepatosplenomegaly. Laboratory examination showed the following: aspartate aminotransferase (AST), 1,215 U/L; alanine aminotransferase (ALT), $887 \mathrm{U} / \mathrm{L}$; alkaline phosphatase (ALP), 1,596 U/L; total bilirubin, $11.5 \mathrm{mg} / \mathrm{dL}$; direct bilirubin, $9.7 \mathrm{mg} / \mathrm{dL}$; total protein, $5.8 \mathrm{~g} / \mathrm{dL}$; IgG, $874 \mathrm{mg} / \mathrm{dL}$; hemoglobin $(\mathrm{Hb})$, $13.9 \mathrm{~g} / \mathrm{dL}$; red blood cell count (RBC), $480 \times 10^{4} / \mu \mathrm{L}$; white blood cell count (WBC), 4,510/ $\mathrm{LL}$ (neutrophils (Nt) $43.4 \%$, lymphocytes (Lym) 45.5\%, monocytes (Mono) $8.8 \%$, eosinophils (Eos) 1.8\%, basophils (Baso) $0.5 \%$ ); and platelets, $17.0 \times 10^{4} / \mu \mathrm{L}$

Nine days after admission, her leukocyte and platelet counts decreased rapidly to $2,000 / \mu \mathrm{L}$, and $6.4 \times 10^{4} / \mu \mathrm{L}$ respectively. We considered her diagnosis to be aplastic anemia associated with hepatitis.

Pathological examination of her liver and bone marrow showed chronic active hepatitis with lobular involvement and piecemeal necrosis, with bridging necrosis and resetting of liver cells (Fig. 1), and slightly hypocellular bone marrow. Her HLA typing showed A2 A24 B7 B35 DR1 DR4. Viral examination was negative for hepatitis A, B, C, D, parvovirus, Epstein-Barr virus, adenovirus, varicella zoster virus, cytomegalovirus, and virus isolation. Autoantibody examination showed anti-nuclear an-

Correspondence to Takeshi Asano, MD, Department of Pediatrics, Nippon Medical School Chiba Hokusoh Hospital, 1715

Kamagari, Inzai, Chiba 270-1694, Japan

E-mail: july1364@nms.ac.jp

Journal Website (http://www2.nms.ac.jp/jnms/) 


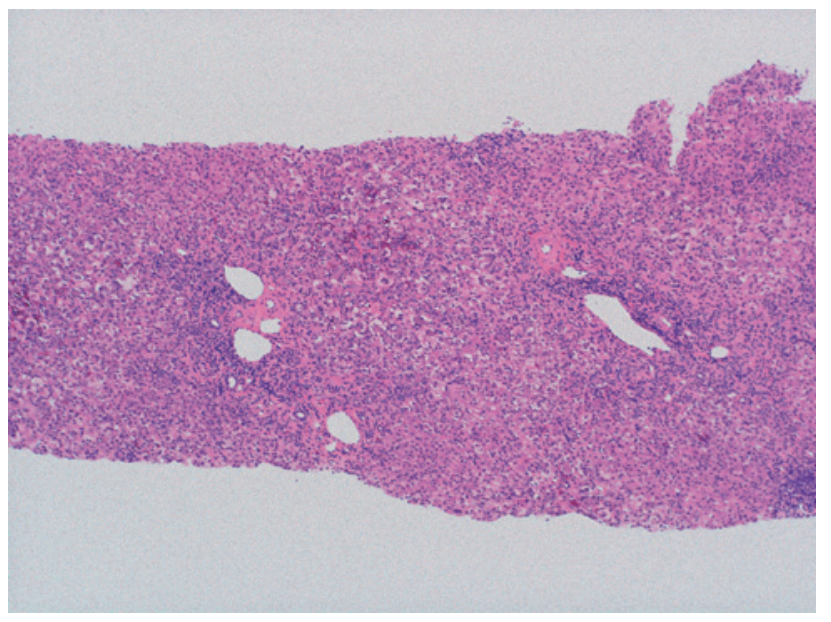

Fig. 1 Pathological findings of the liver (Hematoxylin Eosin staining 400×). Lobular involvement and piecemeal necrosis, with bridging necrosis and resetting of liver cells were observed. The pathological diagnosis was chronic active hepatitis.

tigen $\times 80$ (homogenous), anti-smooth muscle antibody $\times 20$ and other antibodies, including anti-mitochondria antibody, anti-LKM-1 antibody, anti-DNA antibody, antissDNA antibody, anti-dsDNA antibody, anti-ss-A/Ro antibody, anti-ss-B/La antibody, MPO-ANCA, PR3-ANCA, anti-platelet antibody, anti-CL-B2GP1 complex, anticardiolipin IgG, were negative. The criteria for autoimmune hepatitis ${ }^{3}$, female (+2), ALP: AST (or ALT) ratio 1.6 $(+2)$, serum IgG $874 \mathrm{U}(0)$, antinuclear antibodies (ANA) $1: 80(+2)$, anti-mitochondria antibody negative $(0)$, hepatitis viral marker negative $(+3)$, drug history none $(+1)$, average alcohol intake $<25 \mathrm{~g} /$ day $(+2)$, interface hepatitis $(+3)$ and rosetting of liver cells $(+1)$ and HLA DR4 (+1), gave a total score of 17 points, indicating autoimmune hepatitis (pre-treatment). We started to treat her for autoimmune hepatitis with steroids. However, her platelet count further decreased to $20,000 / \mu \mathrm{L}$, despite treatment with high-dose prednisolone therapy and she received several platelet transfusions. One month after starting steroid treatment, her blood examination showed $\mathrm{Hb} 7.6$

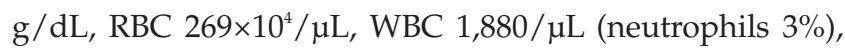
platelet count $32,000 / \mu \mathrm{L}$, ALT $210 \mathrm{U} / \mathrm{L}$ and AST $60 \mathrm{U} / \mathrm{L}$ with blood transfusions. We performed a bone marrow biopsy again but she had developed severe hypoplasia. We finally diagnosed her with severe aplastic anemia and treated her with immune suppressive therapy using anti-thymoglobulin, cyclosporine, and steroids. However, her hematological condition had not improved after the end of immune suppressive therapy. She was treated with hematological stem cell transplantation from her HLA-matched sibling. After transplantation, her hemato- logical and hepatitis status returned to normal.

\section{Materials and Methods \\ Immunohistochemistry}

Paraffin-embedded tissue sections were treated with the following antibodies, in accordance with the manufacturers' instructions and using EnVision FLEX Visualization Systems \& Reagents (DAKO, Agilent Technologies Japan, Ltd., Tokyo, Japan): CD3 (DAKO); CD4 (Japan Tanner Corp., Osaka, Japan); CD8 (DAKO), CD20 (Nichirei Bioscience Inc., Tokyo, Japan); and CD68 (DAKO). The bone marrow specimens were microscopically examined at 400 times magnification. In every specimen three fields were randomly selected in the bone marrow to count the positive cells, from which the mean was taken for analysis. The percentage of positive cells was calculated as the number of positive cell divided by the total number of nuclear cells in the counted areas. Data are expressed as mean \pm standard deviation (SD). Differences between groups were compared using the Mann-Whitney test. A P-value of $<0.05$ was considered statistically significant.

\section{Results}

Histochemical examination of the pretreatment bone marrow specimens showed hypoplastic bone marrow with an increased ratio of CD8-positive cells when compared with a pretreatment bone marrow sample from a patient with aplastic anemia in whom immunosuppressive therapy was successful (Fig. $\mathbf{2 b}$ and Fig. 2 h, Table). The ratio of CD68-positive cells was also significantly higher in the present case when compared to the case with successful immunosuppressive therapy (Fig. 2c and Fig. 2i, Table). In addition, CD8- and CD68-positive cells in the present case remained high after immunosuppressive therapy when compared to the case with successful immunosuppressive therapy (Fig. 2e, 2f, $2 \mathrm{~h}$ and $\mathbf{2 i}$, Table).

\section{Discussion}

Here, we reported on an 8-year-old girl with autoimmune hepatitis who was then diagnosed with severe aplastic anemia and failed to return to a normal hematological status with immunosuppressive therapy. Recently, Wang et al. reported that patients with hepatitisassociated aplastic anemia (HAAA) had a higher CD8+ proportion along with an increased ratio of CD8+/CD4+ when compared to patients with non-HAAA ${ }^{4}$. They also reported that patients with HAAA showed an early infection rate and lower 2-year survival rate, indicating 

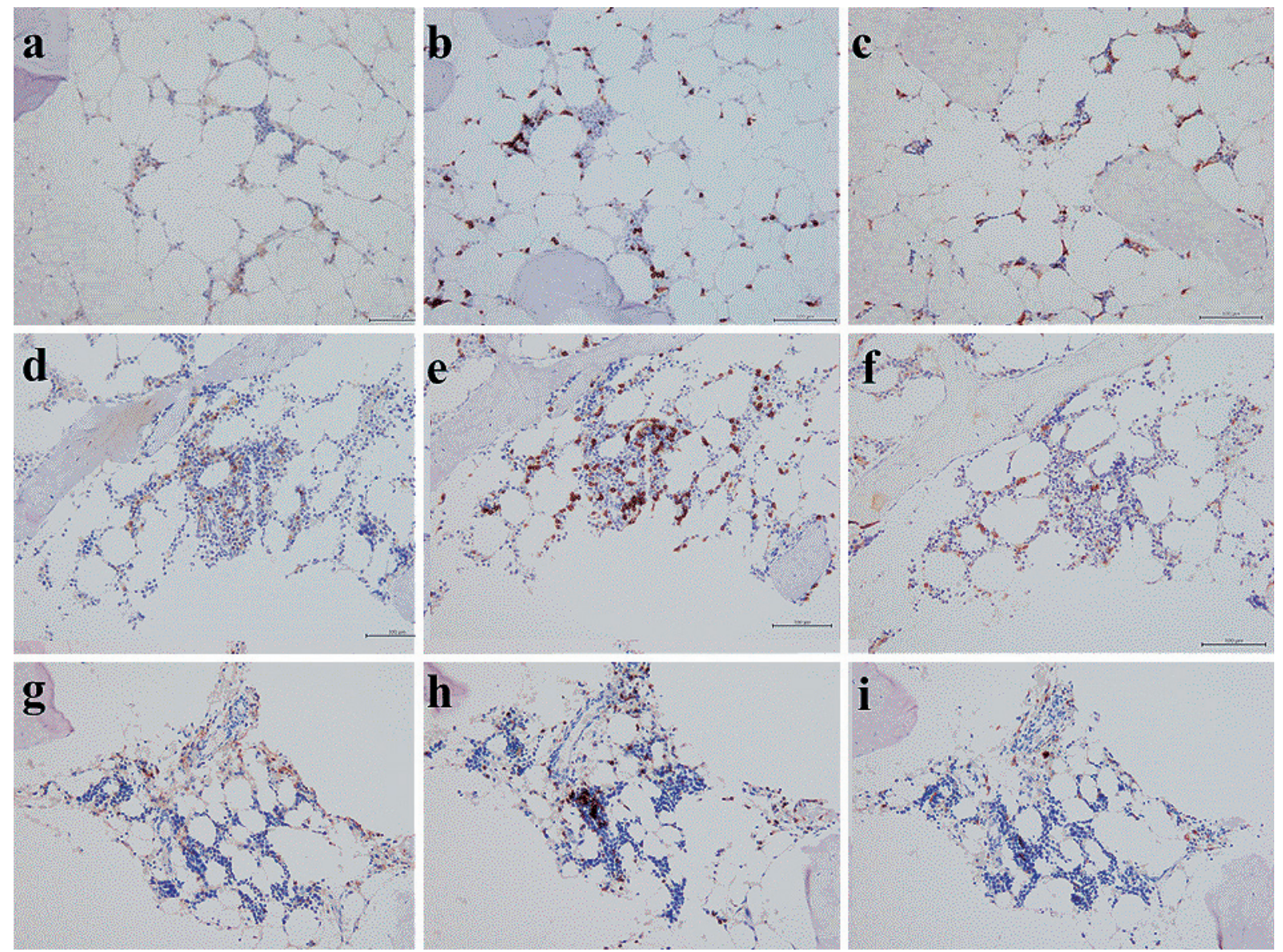

Fig. 2 CD4, CD8, and CD68 staining of the bone marrow (400×). 2a, CD4: present patient prior to immunosuppressive treatment; $2 \mathrm{~b}, \mathrm{CD} 8$ : present patient prior to immunosuppressive treatment; 2c, CD68: present patient prior to immunosuppressive treatment; $2 \mathrm{~d}, \mathrm{CD} 4$ : present patient after immunosuppressive treatment; 2e, CD8: present patient after immunosuppressive treatment; 2f, CD68: present patient after immunosuppressive treatment; $2 \mathrm{~g}$, CD4: patient successfully treated by immunosuppressive therapy prior to immunosuppressive treatment; $2 \mathrm{~h}$, CD8: patient successfully treated with immunosuppressive therapy prior to immunosuppressive treatment; $2 \mathrm{i}$, CD68: patient successfully treated with immunosuppressive therapy prior to immunosuppressive treatment.

that patients with HAAA have a more severe $\mathrm{T}$ cell imbalance and a poorer prognosis than patients with non$\mathrm{HAAA}^{4}$. Our patient also showed increased expression of CD8+ cells in her bone marrow when compared to a patient with non-HAAA who was successfully treated with immunosuppressive therapy. These activated CD8+ lymphocytes could be cytotoxic to hematopoietic cells by increasing interferon- $\gamma$ levels in the bone marrow ${ }^{5}$. The failure of immunosuppressive treatment in our patient might therefore be related to the increased CD8+ lymphocytes.

In addition, we found an increased number of CD68+ cells in the bone marrow of our patient. CD68+ hepatocytes in patients with chronic hepatitis caused by hepatitis B virus showed Fas-L expression ${ }^{6}$ and the primary involvement of Fas-L in hepatitis B is hepatocellular damage $^{7}$. Upregulation of Fas-L expression by the human immunodeficiency virus in human macrophages also medi- ates apoptosis of uninfected T-lymphocytes ${ }^{8}$. Because CD68+ cells in the liver specimens did not show coexpression of CD8, we considered that the CD68+ cells in the bone marrow might not be the same lineage of CD68+ hepatocytes.

It has been reported that CD68 influences macrophage functions, and macrophages that exhibited strong CD68 expression enhanced the motility of human hepatocellular carcinoma cells. In addition, CD68 might be a key receptor-like protein in the signal transduction pathway to regulate variable immune functions of macrophages and be deeply involved in the activation pathways for inflammatory cytokines. These results strongly suggest that CD68 is an important receptor-like glycoprotein in macrophages to regulate their immune function'. Although there have been no studies describing the role of CD68+ cells in the bone marrow of patients with aplastic anemia, increased CD68+ cells in the bone marrow in our 
Table Ratio of positive cells by immunostaining in the bone marrow

\begin{tabular}{llll}
\hline & \multicolumn{1}{c}{ CD4 } & \multicolumn{1}{c}{ CD8 } & CD68 \\
\hline Our patient before immunosuppressive therapy & $0.16+/-0.10$ & $0.44+/-0.10$ & $0.30+/-0.03$ \\
Our patient after immunosuppressive therapy & $0.14+/-0.06$ & $0.37+/-0.09$ & $0.20+/-0.01 *$ \\
A patient with aplastic anemia before immunosuppressive therapy & $0.26+/-0.02$ & $0.14+/-0.02 * * *$ & $0.06+/-0.02 * *, \#$ \\
& & $* * * *$ & \\
\hline
\end{tabular}

*: before vs. after: $\mathrm{p}<0.02$

$* *$ : before vs. control: $\mathrm{p}<0.001$

$* * *$ : before vs. control: $\mathrm{p}<0.03$

$* * * *$ : after vs. control: $\mathrm{p}<0.04$

\#: after vs. control: $\mathrm{p}<0.02$

The bone marrow specimens were microscopically examined at 400 times magnification. In every specimen three fields were randomly selected in the bone marrow to count the positive cells, from which the mean was taken for analysis. The percentage of positive cells was calculated as the number of positive cell divided by the total number of nuclear cells in the counted areas. Data are expressed as mean \pm standard deviation (SD). Differences between groups were compared using the Mann-Whitney test. A Pvalue of $<0.05$ was considered statistically significant.

patient may cause more severe damage to hematopoietic stem cells.

In conclusion, we reported a case of severe aplastic anemia with increased numbers of CD8+ and CD68+ cells in an 8-year-old girl previously diagnosed with autoimmune hepatitis. These increased numbers of lymphocytes and macrophages might have caused more severe damage to hematopoietic stem cells, refractory to immunosuppressive treatment.

Conflict of Interest: The authors declare no conflict of interest.

\section{References}

1. Saadah OI, Smith AL, Hardikar W: Long-term outcome of autoimmune hepatitis in children. Journal of Gastroenterology and Hepatology 2001; 16: 1297-1302.

2. Savage WJ, DeRusso PA, Resar LM, Chen AR, Higman MA, Loeb DM, Jones RJ, Brodsky RA: Treatment of Hepatitis-Associated Aplastic Anemia With High-Dose Cyclophosphamide. Pediatr Blood Cancer 2007; 49: 947951.

3. Alvarez F, Berg PA, Bianchi FB, Bianchi L, Burroughs AK, Cancado EL, Chapman RW, Cooksley WGE, Czaja AJ, Desmet VJ, Donaldson PT, Eddleston ALWF, Fainboim L, Heathcote J, Homberg JC, Hoofnagle JH, Kakumu S, Krawitt EL, Mackay IR, MacSween RNM, Maddrey WC, Manns MP, McFarlane IG, Meyer zum Btischenfelde KH, Micli-Vergani G, Nakanuma Y, Nishioka M, Penner E, Porta G, Portmann BC, Reed WD, Rodes J, Schalm SW,
Scheuer PJ, Schrumpf E, Seki T, Toda G, Tsuji T, Tygstrup $\mathrm{N}$, Vergani D, Zeniya M: International Autoimmune Hepatitis Group Report: review of criteria for diagnosis of autoimmune hepatitis. J Hepatol 1999; 31: 929-938.

4. Wang $\mathrm{H}, \mathrm{Tu} \mathrm{M}, \mathrm{Fu} \mathrm{R}$, Wu Y, Liu H, Xing L, Shao Z: The Clinical and Immune Characteristics of Patients with Hepatitis-Associated Aplastic Anemia in China. Plos One 2014; 9: e98142.

5. Cengiz C, Turhan N, Yolcu OF, Yılmaz S: Hepatitis Associated with Aplastic Anemia: Do CD8 (+) Kupffer Cells Have a Role in the Pathogenesis? Dig Dis Sci 2007; 52: 2438-2443.

6. Tang TJ, Kwekkeboom J, Laman JD, Niesters HGM, Zondervan PE, de Man RA, Schalm SW, Janssen HLA: The role of intrahepatic immune effector cells in inflammatory liver injury and viral control during chronic hepatitis B infection. Journal of Viral Hepatitis 2003; 10: 159-167.

7. Galle PR, Hofmann WJ, Walczak H, Schaller H, Otto G, Stremmel W, Krammer PH, Runkel L: Involvement of the CD95 (APO-1/Fas) receptor and ligand in liver damage. J Exp Med 1995; 182: 1223-1230.

8. Badley AD, McElhinny JA, Leibson PJ, Lynch DH, Alderson MR, Paya CV: Upregulation of Fas ligand expression by human immunodeficiency virus in human macrophages mediates apoptosis of uninfected T lymphocytes. J Virol 1996; 70: 199-206.

9. Okada K, Arai S, Itoh H, Adachi S, Hayashida M, Nakase $\mathrm{H}$, Ikemoto M: CD68 on rat macrophages binds tightly to S100A8 and S100A9 and helps to regulate the cells'immune functions. J Leukoc Biol 2016; 100: 1093-1104.

(Received, February 7, 2018)

(Accepted, March 6, 2018) 